\title{
PENERAPAN METODOLOGI TOZER DALAM PERENCANAAN STRATEGIS SI/TI PADA SEKOLAH TINGGI TEKNIK MUSI
}

\author{
Andri Wijaya dan Arif Aliyanto \\ Sistem Informasi, Fakultas Teknik, Sekolah Tinggi Teknik Musi, Jln.Bangau No.60, Palembang, 30113, \\ Indonesia \\ E-mail: andri0907@gmail.com
}

\begin{abstract}
At the present time, each organization is required to have differentiation and innovation in order to increase competitiveness against its competitors and increase profit organization. Higher education is a business organization engaged in services can not be separated from the reach of globalization, competition and the use of information systems and information technology (IS/IT) in the business process. Sekolah Tinggi Teknik Musi (STT Musi) is an educational institution in the city of Palembang are already using the IS / IT in its operations, but to do the planning and management of IS / IT is aligned with business strategy and vision is still not optimum . Therefore, to optimize the use of IS / IT is right that supports the business strategy and vision and also to improve the business strategy in the future in line with the vision and mission planning needed SI / IT is mature. Therefore this study will result in a strategic planning model of IS / IT in accordance with the business strategy and vision of the STT Musi . This plan will use the methodology proposed by Tozer and the expected results of this study will address the needs of strategic planning model SI / IT from STT Musi which has been much needed in the face of a very high level of competition at this time with the achievement of measurable results and comprehensive.
\end{abstract}

Keywords: Business Strategy, IS/IT Strategic Plan, Tozer Metodology

\begin{abstract}
Abstrak
Pada saat dewasa ini, setiap organisasi dituntut untuk memiliki diferensiasi dan inovasi guna untuk meningkatkan daya saing terhadap pesaingnya dan meningkatkan profit organisasi tersebut. Pendidikan tinggi salah satu organisasi bisnis yang bergerak dibidang jasa tidak terlepas dari jangkauan globalisasi, persaingan dan penggunaan sistem informasi dan teknologi informasi (SI/TI) di dalam proses bisnisnya. Sekolah Tinggi Teknik Musi (STT Musi) merupakan institusi pendidikan di kota Palembang yang sudah menggunakan SI/TI dalam operasionalnya, tetapi untuk melakukan perencanaan dan pengelolaan SI/TI yang sejalan dengan strategi bisnis dan visi misi masih belum optimal dilakukan. Oleh karena itu untuk mengoptimalkan penggunaan SI/TI yang tepat yang mendukung strategi bisnis dan visi misi dan juga untuk memperbaiki strategi bisnis di masa akan datang yang selaras dengan visi misi dibutuhkanlah perencanaan SI/TI yang matang. Maka dari itu pada penelitian ini akan menghasilkan sebuah model perencanaan strategis SI/TI yang sesuai dengan strategi bisnis dan visi misi dari STT Musi. Perencanaan ini akan menggunakan metodologi yang dikemukakan oleh Tozer dan diharapkan hasil dari penelitian ini akan menjawab kebutuhan model perencanaan strategis SI/TI dari STT Musi yang selama ini sangat diperlukan dalam menghadapi tingkat persaingan yang sangat tinggi pada saat ini dengan hasil pencapaian yang terukur dan komprehensif.
\end{abstract}

Kata Kunci: Strategi Bisnis, Perencanaan Strategis SI/TI, Metodologi Tozer

\section{Pendahuluan}

Pada saat dewasa ini, setiap organisasi dituntut untuk memiliki diferensiasi dan inovasi guna untuk meningkatkan daya saing terhadap pesaingnya dan meningkatkan profit organisasi tersebut. Maka setiap organisasi mencoba untuk menerapkan sistem informasi dan teknologi informasi untuk dapat meningkatkan efesiensi dan efektifitas dalam proses bisnis, dan juga agar dapat memberikan nilai tambah yaitu berupa competitive advantage dalam persaingan bisnis. Pendidikan tinggi salah satu institusi bisnis yang bergerak dibidang jasa tidak terlepas dari jangkauan globalisasi dan penggunaan sistem informasi dan teknologi informasi di dalam proses bisnisnya.

Sekolah Tinggi Teknik Musi merupakan salah satu institusi pendidikan di kota Palembang yang sudah menerapkan sistem informasi dan tek- 


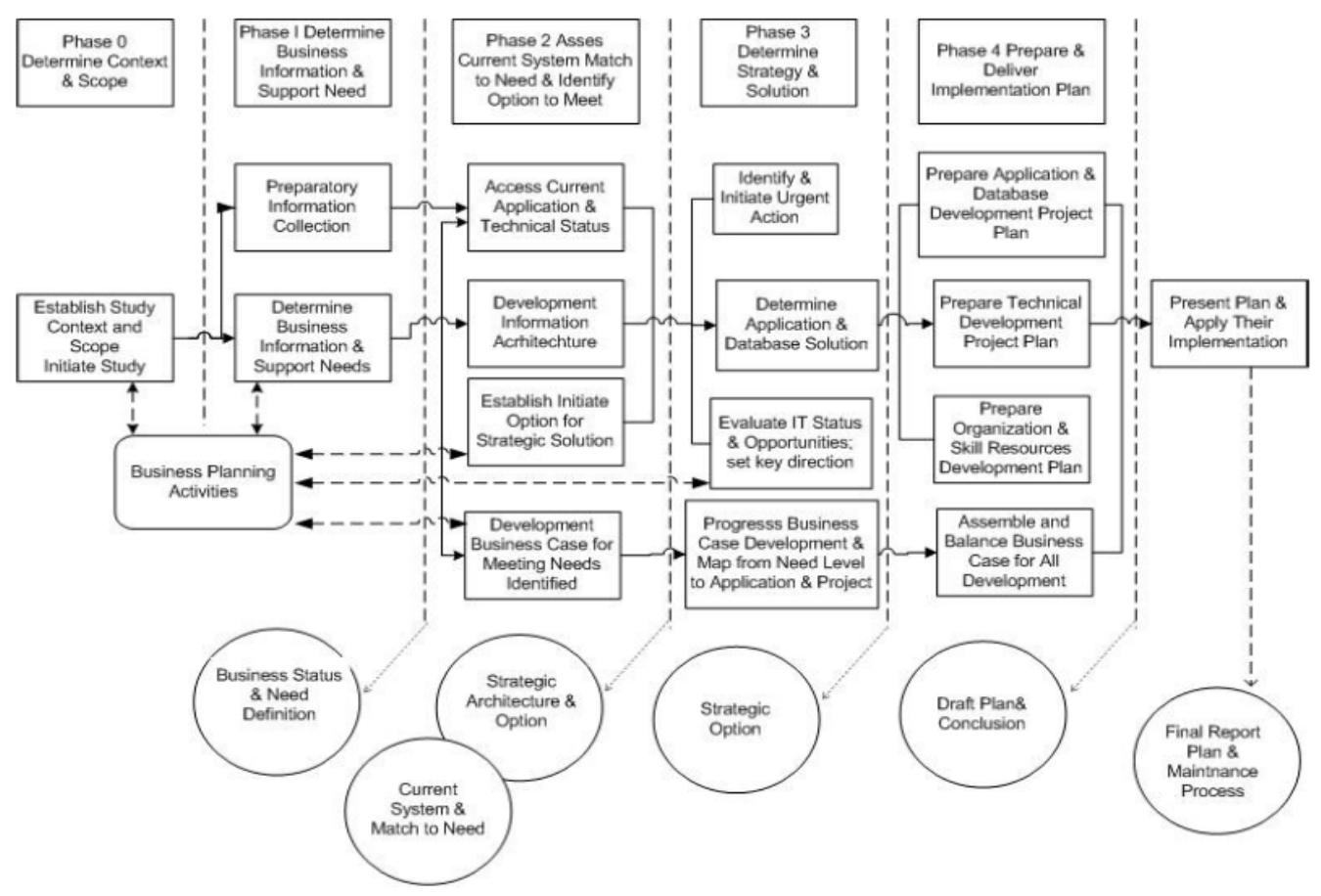

Gambar 1. Tahapan Metodologi Tozer

nologi informasi didalam operasionalnya, tetapi SI/ TI tersebut belum digunakan secara maksimal dan kurangnya keselarasan dengan visi misi serta strategi bisnis dari STT Musi sendiri. Untuk memaksimalkan SI/TI tersebut perlunya dilakukan perencanaan SI/TI yang mendukung visi misi dan strategi bisnis dari STT Musi.

Dalam melakukan perencanaan strategis SI/ TI tersebut akan digunakan metodologi Tozer sehingga hasil dari penelitian ini adalah sebuah model perencanaan strategis SI/TI yang mendukung strategis bisnis yang sudah ada pada STT musi dan hasil ini juga diharapkan dapat menjawab kebutuhan SI/TI yang diperlukan oleh STT Musi baik pada saat ini dan masa yang akan datang.

\section{Metodologi}

Untuk defenisi perencanaan strategis sistem informasi yang dikemukakan oleh Ward and Peppard adalah PSSI merupakan proses identifikasi kebutuhan aplikasi sistem informasi berbasis komputer yang akan mendukung organisasi dalam pelaksanaan rencana bisnis dan merealisasikan tujuan bisnisnya. Selain itu perencanaan strategis SI/TI juga menjelaskan berbagai alat, teknik dan kerangka kerja bagi manajemen untuk menyelaraskan strategi SI/TI dengan strategi bisnis, bahkan mencari kesempatan baru melalui penerapan teknologi yang inovatif [2].

Dalam proses melakukan perencanaan strate- gis SI/TI salah satu faktor yang penting adalah penggunaan metodologi. Metodologi perencanaan strategis SI/TI yang digunakan pada penelitian ini yakni metodologi perencanaan SI/TI versi Tozer. Metodologi versi ini merupakan pendekatan yang praktis dan formal yang berdasarkan pada konsep strategi bisnis yang menentukan cara mengeksploitasi sumber daya SI/TI beserta pemanfaatannya. Gambar 1 menggambarkan tahapan perencanaan strategis SI/TI versi Tozer [3].

Berikut ini beberapa teori-teori tentang tools yang digunakan dalam menyelesaikan tahapan-tahapan dalam metodologi Tozer dengan mengacu pada Gambar 2.

\section{Value Chain}

Value Chain (rantai nilai) adalah metode sistematis untuk memeriksa seluruh kegiatan organisasi dan untuk mengetahui interaksi yang digunakan organisasi sebagai sumber kegiatan bersaing seperti yang diungkapkan oleh Callon [4].

\section{Critical Success Factor}

Critical Success Factor (CSF - Faktor Kritis Kesuksesan) seperti yang ditunjukkan pada Gambar 3, merupakan suatu ketentuan dari orga-nisasi dan lingkungannya yang berpengaruh pada keberhasilan atau kegagalan organisai yang diungkapkan Tozer [3]. 


\begin{tabular}{|c|c|c|c|c|c|c|}
\hline \multicolumn{2}{|l|}{$\begin{array}{l}\text { Support activities } \\
\text { Infrastructure }\end{array}$} & \multicolumn{4}{|c|}{ - Legal, accounting, financial management } & \\
\hline \multicolumn{2}{|l|}{$\begin{array}{l}\text { Human-resource } \\
\text { management }\end{array}$} & \multicolumn{4}{|c|}{$\begin{array}{l}\text { - Personnel, pay, recruitment, training, } \\
\text { manpower planning, etc. }\end{array}$} & \\
\hline \multicolumn{2}{|c|}{$\begin{array}{l}\text { Product and technology } \\
\text { development }\end{array}$} & \multicolumn{4}{|c|}{$\begin{array}{l}\text { - Product and process design, production engineering, } \\
\text { market testing, R\&D, etc. }\end{array}$} & \\
\hline \multicolumn{2}{|l|}{ Procurement } & \multicolumn{4}{|c|}{$\begin{array}{l}\text { - Supplier management, funding, } \\
\text { subcontracting, specification }\end{array}$} & \\
\hline $\begin{array}{l}\text { INBOUND } \\
\text { LOGISTICS } \\
\text { For example: } \\
\text { quality control; } \\
\text { receiving; } \\
\text { raw materials } \\
\text { control; etc. }\end{array}$ & $\begin{array}{l}\text { OPERA } \\
\text { For exa } \\
\text { manufa } \\
\text { packag } \\
\text { produc } \\
\text { control } \\
\text { quality } \\
\text { mainter } \\
\text { etc. }\end{array}$ & $\begin{array}{l}\text { IONS } \\
\text { nple: } \\
\text { turing; } \\
\text { g; } \\
\text { on } \\
\text { ontrol; } \\
\text { ance; }\end{array}$ & $\begin{array}{l}\text { OUTBOUND } \\
\text { LOGISTICS } \\
\text { For example: } \\
\text { finishing goods; } \\
\text { order handling; } \\
\text { dispatch; } \\
\text { delivery; } \\
\text { invoicing; etc. }\end{array}$ & $\begin{array}{l}\text { SALES \& } \\
\text { MARKETING } \\
\text { For example: } \\
\text { customer } \\
\text { management; } \\
\text { order taking; } \\
\text { promotion; } \\
\text { sales analysis; } \\
\text { market } \\
\text { research; etc. }\end{array}$ & $\begin{array}{l}\text { SERVICING } \\
\text { For example: } \\
\text { warranty; } \\
\text { maintenance; } \\
\text { education and } \\
\text { training; } \\
\text { upgrades; etc. }\end{array}$ & \\
\hline
\end{tabular}

Gambar 2. Value Chain

\section{SWOT Analysis}

Tozer [3] mengatakan SWOT merupakan identifikasi factor internal (Strength and Weakness - kekuatan dan Kelemahan) dan factor eksternal (Opportunity and Threat - Peluang dan Ancaman) dari organisasi secara sistematis untuk merumuskan strategi organisasi.

TABEL 1 DIAGRAM SWOT

\begin{tabular}{cll} 
& \multicolumn{2}{c}{ DiAGRAM SWOT } \\
\hline & \multicolumn{1}{c}{ S(Strength) } & W (Weakness) \\
\hline O & $\begin{array}{l}\text { Strategi SO: Strate- } \\
\text { gi yang mengguna- } \\
\text { kan kekuatan untuk } \\
\text { memanfatkan pe- } \\
\text { luang }\end{array}$ & $\begin{array}{l}\text { Strategi WO: Stra- } \\
\text { tegi yang memini- } \\
\text { malkan kelemahan } \\
\text { untuk memanfaat- } \\
\text { kan peluang }\end{array}$ \\
Threat) & $\begin{array}{l}\text { Strategi ST: Strate- } \\
\text { gi yang mengguna- } \\
\text { kan kekuatan unutk } \\
\text { mengatasi ancaman }\end{array}$ & $\begin{array}{l}\text { Strategi WT: Stra- } \\
\text { tegi yang memini- } \\
\text { malkan kelemahan } \\
\text { untuk menghindari } \\
\text { ancaman }\end{array}$ \\
\hline
\end{tabular}

\section{McFarlan Grid}

McFarlan dan McKenney mengemukakan sebuah model untuk mengkategorikan sistem informasi ke dalam empat golongan yaitu pendukung (support), High Potential, Key Operational dan Strategic.

TABEL 2.

\begin{tabular}{ll}
\multicolumn{2}{c}{ MCFARLAN GRID } \\
\hline \multicolumn{1}{c}{ Strategic } & \multicolumn{1}{c}{ High Potential } \\
\hline $\begin{array}{l}\text { Aplikasi yang kritikal untuk } \\
\text { keberlanjutan strategi bisnis } \\
\text { di masa depan }\end{array}$ & $\begin{array}{l}\text { Aplikasi yang mungkin pen- } \\
\text { ting dalam mencapai kesuk- } \\
\text { sesan di masa depan }\end{array}$ \\
$\begin{array}{ll}\text { Aplikasi yang pada saat ini } \\
\text { digunakan enterprise untuk } \\
\text { kesuksesan }\end{array}$ & $\begin{array}{l}\text { Aplikasi yang berharga tapi } \\
\text { tidak kritikal untuk kesukse- } \\
\text { san }\end{array}$ \\
\hline Key Operational & \multicolumn{1}{c}{ Support } \\
\hline
\end{tabular}

\section{Five Forces Competitive Model}

Menurut Porter [5] strategi yang berbasis kompetisi adalah rencana dari perusahaan untuk memenangkan persaingan dengan mencapai keunggulan daya saing (Competitive advantage) yang melebihi kompetitornya atau dengan mereduksi sisi competitive advantage dari pesaing.

\section{Tozer}

Metodologi yang digunakan dalam penelitian ini adalah metodologi Tozer. Untuk menyelesaikan permasalahan akan digunakan metodologi yang diturunkan dari "Kerangka Kerja Proses Perencanaan Sistem Informasi dari Tozer".

Langkah-langkah yang diambil mencakup beberapa langkah berdasarkan pengumpulan data, serta analisis lingkungan bisnis perusahaan dan interpretasi data. Selanjutnya tahapan tersebut akan menghasilkan portofolio perencanaan strategis SI/ TI [6]. Penjelasan masing-masing tahapan disampaikan pada Gambar 5.

\section{Hasil dan Analisa}

Pada bagian ini penulis akan mencoba mengidentifikasi dan menganalisis hal-hal yang berhubungan langsung dan tidak langsung dengan core bisnis perusahaan. Jika dihubungkan dengan fase yang terdapat pada metodologi Tozer, pada saat ini fase yang dibahas yaitu fase 3 (tiga) yaitu mengevaluasi kesesuaian sistem dengan kebutuhan bisnis saat ini. Pada analisis fase 3 (tiga) ini akan digunakan beberapa tools untuk menganalisa. Untuk analisis fase 3 (tiga) sebagai berikut :

\section{Analisa Five Forces Competitive Model}




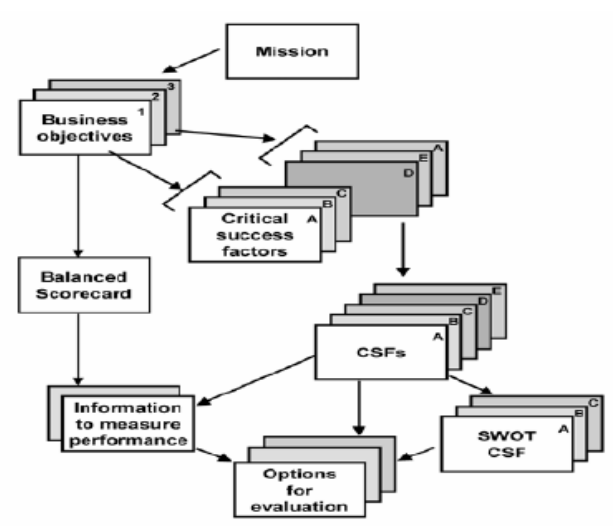

Gambar 4. CSF Pemrosesan Dasar

Analisa ini (Gambar 4) bertujuan untuk mengetahui apa saja di luar sana yang dapat mempengaruhi jalannya bisnis perusahaan baik itu menghasilkan dampak langsung maupun tidak langsung terhadap bisnis perusahaan. Hasil dari analisa ini nantinya akan dipetakan ke dalam analisis SWOT. Untuk hasil dari analisa ini dapat dilihat pada Gambar 6.

\section{Analisa Value Chain}

Analisa Value Chain ini dilakukan untuk pemetaan seluruh proses bisnis yang dijalankan oleh STT Musi, pada analisa Value Chain ini dibagi menjadi

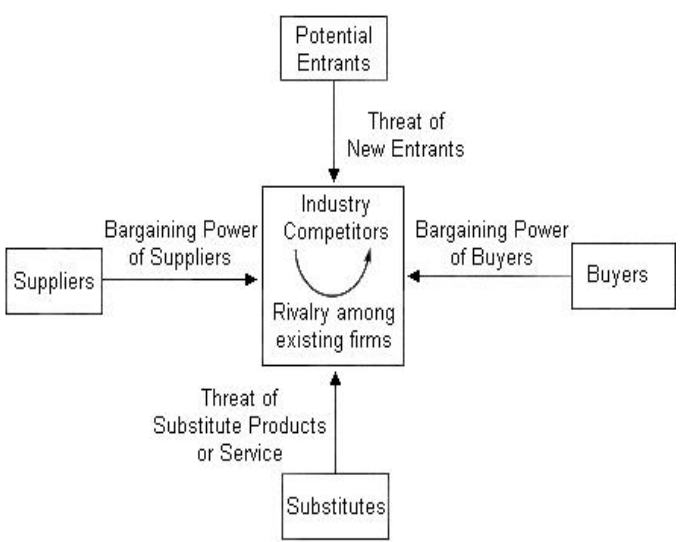

Gambar 3. Porter's Five Forces Model Competitive

2 (dua) kategori yaitu aktivitas utama dan aktivitas pendukung. Untuk penjelaskan aktivitas utama dan aktivitas pendukung sebagai berikut :

\section{Aktivitas Utama}

Aktivitas-aktivitas yang termasuk didalam aktivitas utama pada value chain STT Musi adalah sebagai berikut: 1) Penerimaan mahasiswa baru dari berbagai jalur (jalur regular,beasiswa, kerja sama, jalur transfer; 2) Persiapan Ujian Saringan Masuk; 3) Pengisian rencana perkuliahan; 4) Penjadwalan Perkuliahan; 5) Melakukan kegiatan belajar meng-

TABEL 3.

APLIKASI SI/TI SAAT INI BERDASARKAN VALUE CHAIN UNTUK AKTIVITAS UTAMA

\begin{tabular}{|c|c|c|c|}
\hline Value chain & Kegiatan & $\begin{array}{l}\text { Unit Kerja yang } \\
\text { Terlibat }\end{array}$ & Sistem Saat Ini \\
\hline Inbound Logistic & $\begin{array}{l}\text { Penerimaan mahasis-wa baru dari berbagai jalur } \\
\text { Persiapan ujian sari-ngan masuk }\end{array}$ & $\begin{array}{l}\text { Marketing } \\
\text { BAAK }\end{array}$ & $\begin{array}{l}\text { Ms. Office / Ms. } \\
\text { Excel Form Soal } \\
\text { Ujian }\end{array}$ \\
\hline Operation & $\begin{array}{l}\text { Pengisian rencana perkuliahan } \\
\text { Penjadwalan perkuliahan } \\
\text { Melakukan kegiatan belajar mengajar } \\
\text { Absensi Kehadiran mahasiswa } \\
\text { Pelaksanaan ujian semester } \\
\text { Pengelolaan nilai mahasiswa } \\
\text { Pengadaan buku perpustakaan } \\
\text { Pengelolaan buku } \\
\text { Pengelolaan data mahasiswa reguler dan beasiswa } \\
\text { Pengendalian proses pengolahan data penelitian dan } \\
\text { pengabdian } \\
\text { Evaluasi kinerja dosen }\end{array}$ & $\begin{array}{l}\text { BAAK } \\
\text { Dosen }\end{array}$ & $\begin{array}{lr}\text { Portal akademik, Ms. } \\
\text { Office/Ms. } & \text { Excel, } \\
\text { Form Absensi, Form } \\
\text { Soal Ujian, Form } \\
\text { Evaluasi } & \text { Kinerja } \\
\text { Dosen, } & \text { Form } \\
\text { Penelitian } & \text { dan } \\
\text { Pengabdian } & \end{array}$ \\
\hline $\begin{array}{l}\text { Outbound } \\
\text { Logistic }\end{array}$ & Kerjasama STT Musi dengan pihak dalam dan luar negeri & STT Musi & Email Service \\
\hline $\begin{array}{l}\text { Sales } \\
\text { Marketing }\end{array}$ & $\begin{array}{l}\text { Melakukan pemasangan iklan di gereja-gereja dan di media } \\
\text { massa } \\
\text { Melakukan penyebaran brosur ke sekolah-sekolah terutama } \\
\text { sekolah basis } \\
\text { Mengikuti setiap kegiatan promosi yang diselenggarakan oleh } \\
\text { sekolah basis }\end{array}$ & $\begin{array}{l}\text { Marketing, } \\
\text { BAAK, } \\
\text { Dosen }\end{array}$ & Brosur manual \\
\hline Services & $\begin{array}{l}\text { Pelatihan dosen } \\
\text { Pelayanan informasi kepada civitas akademika } \\
\text { Pelayanan informasi publik } \\
\text { Pelayanan akademik dosen }\end{array}$ & $\begin{array}{l}\text { Divisi customer } \\
\text { ser-vice, } \\
\text { Divisi service }\end{array}$ & $\begin{array}{l}\text { Form pelatihan, } \\
\text { Portal aka-demik (SI } \\
\text { Akademik), Web-site }\end{array}$ \\
\hline
\end{tabular}


TABEL 4.

APLIKASI SI/TI SAAT INI BERDASARKAN VALUE CHAIN UNTUK AKTIVITAS PENDUKUNG

\begin{tabular}{|c|c|c|c|}
\hline Value chain & Kegiatan & $\begin{array}{l}\text { Unit Kerja yang } \\
\text { Terlibat }\end{array}$ & Sistem Saat Ini \\
\hline $\begin{array}{l}\text { Corporate } \\
\text { infrastruktur }\end{array}$ & $\begin{array}{l}\text { Promosi dan marketing } \\
\text { Biro administrasi Akademik } \\
\text { Biro administrasi umum dan keuangan }\end{array}$ & $\begin{array}{l}\text { Marketing } \\
\text { BAAK } \\
\text { BAU }\end{array}$ & $\begin{array}{l}\text { Brosur manual- } \\
\text { Mic.Office (Mic.Excel) } \\
\text { Portal akademik (SI Aka- } \\
\text { demik) }\end{array}$ \\
\hline $\begin{array}{l}\text { Human } \\
\text { Resources } \\
\text { Management }\end{array}$ & $\begin{array}{l}\text { Kompensasi (Gaji, tunjangan/Tunjangan, insentive) } \\
\text { Pengembangan SDM }\end{array}$ & Semua divisi & $\begin{array}{l}\text { Mic.Office (Mic.Excel) } \\
\text { Form monitoring dan eva- } \\
\text { luasi karyawan }\end{array}$ \\
\hline $\begin{array}{l}\text { Technology } \\
\text { Development }\end{array}$ & Teknologi informasi & Semua divisi & - \\
\hline Procurement & Pengadaan/ pembelian barang kebutuhan & Divisi Pemasaran & Email Service \\
\hline
\end{tabular}

ajar; 6) Pelaksanaan Ujian Semester; 7) Pengelolaan Nilai Mahasiswa; 8) Pengadaan Buku perpustakaan; 9) Pengolahan Buku Perpustakaan; 10) Pengolahan data mahasiswa regular dan beasiswa; 11) Pengendalian Proses dan Pengolahan data Penelitian dan Pengabdian; 12) Evaluasi kinerja Dosen; 13) Kerja sama STT Musi dengan pihak dalam dan luar negeri; 14) Melakukan pemasangan iklan promosi dan brosur-brosur dibagikan ke sekolahsekolah terutama sekolah basis; 15) Mengikuti setiap kegiatan promosi yang sering diadakan sekolahsekolah basis (Contoh : Expo Pendidikan); 16) Pelatihan Dosen; 17) Pelayanan informasi kepada Civitas Akademika (Contoh: Informasi Lowongan Pekerjaan); 18) Pelayanan Informasi Publik; 19) Pelayanan Akademik Dosen.

\section{Aktivitas Pendukung}

Aktivitas yang termasuk didalam aktivitas pendukung pada Value Chain STT Musi sebagai berikut: 1) Promosi dan Marketing; 2) Biro Administrasi Akademik; 3) Biro Administrasi Umum dan Keuangan; 4) Kompensasi; 5) Pengembangan SDM; 6) Teknologi Informasi; 7) Pengadaan dan Pembelian Barang.

\section{Pemetaan Aplikasi McFarlan Grid}

Berdasarkan dari pemetaan analisis Value Chain diatas langkah berikutnya akan ditentukan solusi IS/IT yang berpeluang untuk mendukung seluruh aktivitas dari organisasi yang ada pada value chain,

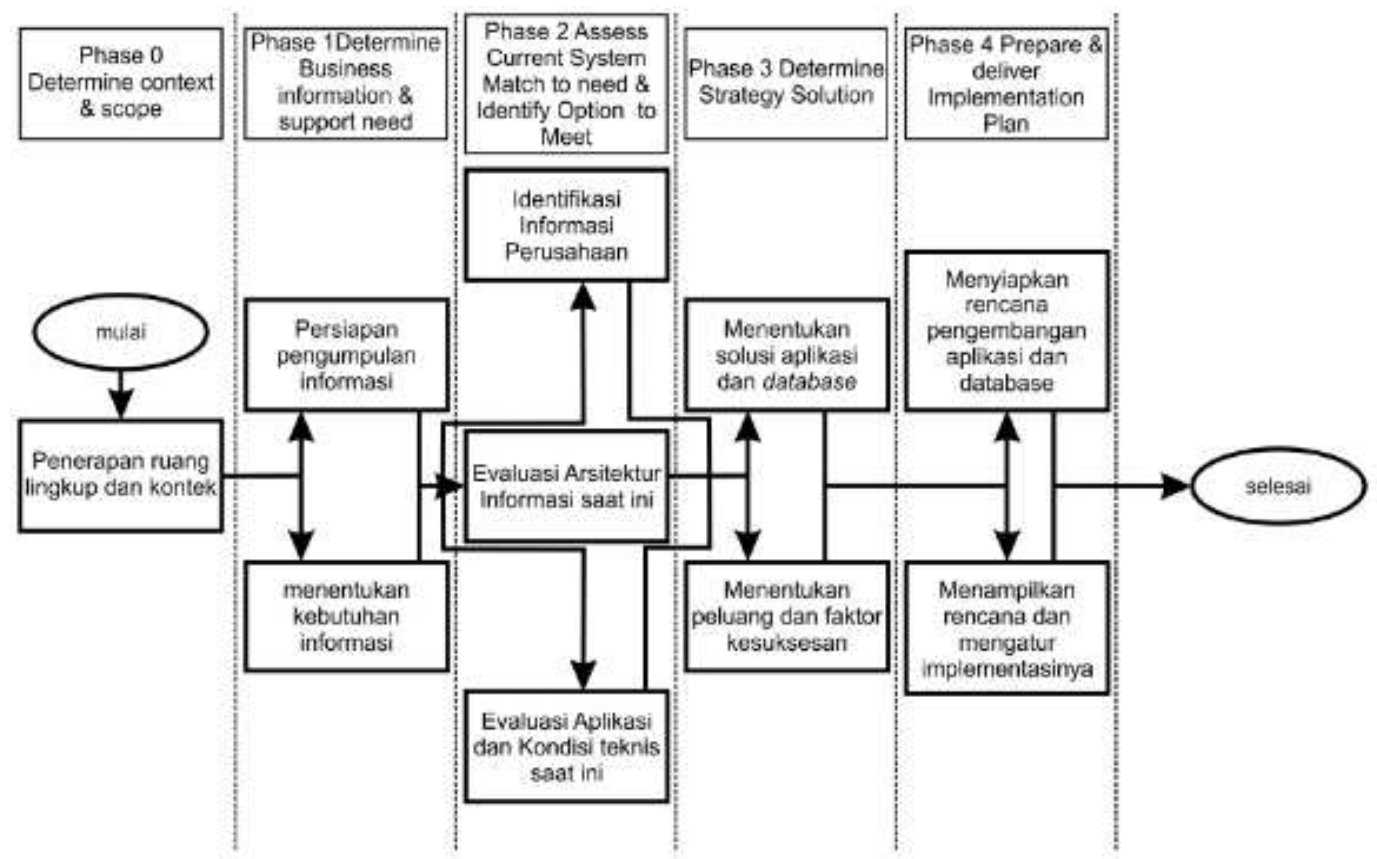

Gambar 5. Kerangka Kerja Penelitian 
100 Journal of Information Systems, Volume 9, Issue 2, October 2013

TABEL 5. PORTOFOLIO APLIKASI EXISTING PADA STT MUSI

\begin{tabular}{cc}
\hline Strategic & High Potential \\
\hline- & - \\
Portal Akademik (Si & Email Service \\
Akademik) & Ms.Office \\
& Windows Xp \\
& Website \\
\hline Key Operational & Support \\
\hline
\end{tabular}

baik itu dari sisi aktivitas utama maupun pendukung. Dengan demikian akan terlihat jelas penggunaan IS/IT berdasarkan koordinasi dan aliran informasi antar bagian di STT Musi. Hasil identifikasi solusi IS/IT STT Musi pada saat ini berdasarkan value chain dapat dilihat pada Tabel 3 dan Tabel 4.

Pada langkah selanjutnya hasil dari value chain yang menampilkan solusi IS/IT dari STT Musi akan dipetakan ke model McFarlan's Strategic Grid guna untuk mendapatkan gambaran tentang kontribusi dari setiap aplikasi SI yang ada di STT Musi terhadap pelaksanaan tugas organisasi seperti ditunjukan pada Tabel 5.

\section{Kesimpulan}

Hasil dari penelitian ini nantinya berupa model perencanaan strategis SI/TI yang selaras dengan visi, misi dan strategi bisnis STT Musi dan menjadikan STT Musi mempunyai competitive Advantages (keunggulan dalam Persaingan), serta penelitian ini juga bermaksud untuk memaksimalkan penggunaan sumber daya yang dimiliki oleh STT Musi khususnya SI/TI. Sampai diterbitkannya tulisan ini, penelitian masih berlangsung dan sedang dalam tahap fase 4 dan fase 5 yang sesuai dengan metodologi perencanaan strategis SI/TI Tozer yang digunakan.

\section{Ucapan Terima Kasih}

Tulisan ini merupakan bagian dari Program Hibah Penelitian dosen Pemula tahun 2013 yang dibiayai DIPA Direktorat Penelitian dan Pengabdian Ma-

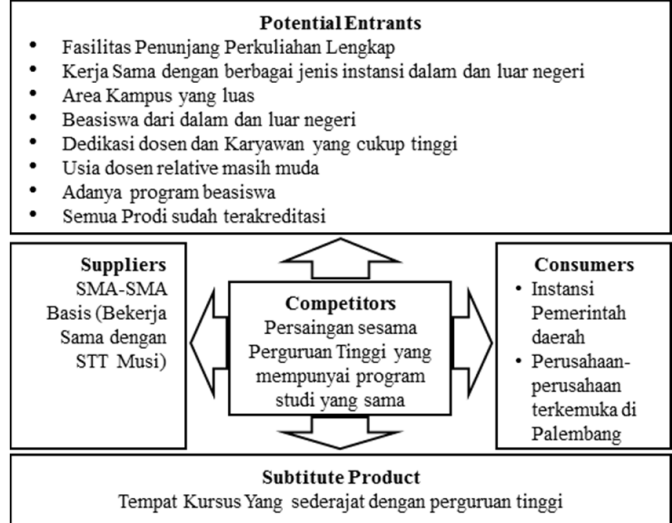

Gambar 6. Pemetaan Hasil Five Forces Model

syarakat, Direktorat Jenderal Pendidikan Tinggi. Dan ucapan terima kasih kami sampaikan kepada Direktorat Jenderal Pendidikan Tinggi atas kesempatan yang telah diberikan kepada kami.

\section{Referensi}

[1] Indrajit, Richardus Eko, dan Djokopranoto Richardus, Manajemen Perguruan Tinggi Moderen, CV. Andi Offset, Yogyakarta, 2006.

[2] Ward, J and Pepard Joe, Strategic Planning for Information System, third Edition, John Wiley \&Sons Ltd, England, 2002.

[3] Tozer, E.E., Strategic IS/IT Palnning: Profesional series, Butterworth-Heinemann, 1996.

[4] Callon, D.J., Competitive Advantage Through Information Technology, International Edition, Mc. Graw-Hill, Singapore, 1996.

[5] Porter, Michael E., Competitive advantage : Creating and sustaining superior performan$c e$, The Free Press. New York, 1998.

[6] W. Andri, "Perencanaan Strategis SI/TI Pada Perusahaan Otomotif Dengan Menggunakan Metodologi Tozer," Karya Akhir, Magister Teknologi Informasi, Universitas Indonesia, Jakarta, 2011. 